\title{
Research priorities of people living with Turner syndrome
}

\author{
David E. Sandberg ${ }^{1}$ (1) | Dianne Singer ${ }^{1}$ | Benjamin Bugajski ${ }^{1}$ | \\ Achamyeleh Gebremariam $^{1}$ | Teresa Scerbak ${ }^{1}$ | Kathleen L. Dooley Maley ${ }^{2}$ | \\ Cindy Scurlock ${ }^{2}$ | Denise Culin ${ }^{3}$ | Sally Eder ${ }^{1}$ | Michael Silberbach ${ }^{4}$
}

\author{
${ }^{1}$ Department of Pediatrics and the Susan B. \\ Meister Child Health Evaluation Research \\ (CHEAR) Center, University of Michigan, Ann \\ Arbor, Michigan \\ ${ }^{2}$ Turner Syndrome Society of the United \\ States, Houston, Texas \\ ${ }^{3}$ Turner Syndrome Global Alliance, Overland \\ Park, Kansas \\ ${ }^{4}$ Department of Pediatrics, Division of \\ Pediatric Cardiology, Oregon Health and \\ Science University, School of Medicine, \\ Portland, Oregon \\ Correspondence \\ David E. Sandberg, PhD, Department of \\ Pediatrics and the Susan B. Meister Child \\ Health Evaluation Research (CHEAR) Center, \\ University of Michigan, 300 North Ingalls \\ Street, Rm 6C23, Ann Arbor, MI 48109-5456. \\ Email: dsandber@med.umich.edu \\ Funding information \\ Eunice Kennedy Shriver National Institute of \\ Child Health and Human Development, Grant/ \\ Award Numbers: R01 HD093450, R13 \\ HD096857 and a Patient-Centered Outcomes \\ Research Institute (PCORI) Engagement Award
}

Despite major discoveries, traditional biomedical research has not always addressed topics perceived as priorities by patients and their families. Patient-centered care is predicated on research taking such priorities into account. The present study surveyed women with Turner syndrome (TS; $18+$ years; $n=543$ ), parents of women with TS $(n=232)$, and parents of younger daughters with TS $(<18$ years; $n=563$ ), regarding their priorities for research. The study also included a quantitative audit of research categorized as either predominantly biomedical or psychological in the medical and other scientific literature. The overwhelming majority of all surveyed stakeholders ( $84 \%$ and higher) rated both biomedical and psychological research in TS as "very important," yet only approximately $9 \%$ of published research focused on psychological aspects of TS. The odds of women with TS identifying psychological research as "most important" was significantly lower (OR: $0.607 ; 95 \% \mathrm{Cl}$ : 0.375, 0.982] than the odds of parents making the same prioritization. Despite the majority of participants rating research as very important, only approximately half-rated participation in research as similarly important. The majority of respondents in all three groups (59\%-73\%) indicated they would "very likely" participate in research pertaining to eating or nutrition, quality of life, or genetic studies in TS. Substantially fewer expressed similar eagerness to participate in studies involving the study of a new medicine or medical device. Increased engagement of patient and family stakeholders in research requires that investigators select topics of study important to that community.

\section{KEYWORDS}

patient-centered, research priorities, survey, Turner syndrome

\section{1 | INTRODUCTION}

Traditional biomedical research has delivered major advances, but has not always been directed toward answering the questions and priorities of patients and their families. In 2001, the Institute of Medicine (currently the Health and Medicine Division of the National Academies) published the report Crossing the Quality Chasm: A New Health System for the 21st Century (Committee on Quality of Health Care in America \& Institute of Medicine, 2001). The report established six aims to raise the quality of healthcare. Aim 3 addressed "patientcenteredness," which focused on "providing care that is respectful of and responsive to individual patient preferences, needs, and values and ensuring that patient values guide all clinical decisions." Achieving this aim is predicated on investigating patient and family priorities for healthcare and, by implication, conducting research that reflects these priorities.
The recent updated clinical practice guideline for Turner syndrome (TS) underscores both the biomedical and psychological (i.e., neurocognitive/behavioral/emotional/social) aspects of the condition (Gravholt et al., 2017). The section on neurocognitive and behavioral aspects (pp. G43-G49) goes far beyond the preceding TS clinical practice guideline (Bondy for the Turner Syndrome Study Group, 2007) with respect to detailing the neurocognitive, academic, social, and psychological phenotypes associated with TS. This neurocognitive profile has repeatedly been shown to place the psychological adaptation and quality of life of girls and women at risk (Gravholt et al., 2017, Table 9), yet it is unclear whether this topic receives adequate attention from researchers or clinicians. The aims of this study were, therefore, twofold: (a) to conduct a survey of affected stakeholders regarding the perceived importance of biomedical versus psychological research in TS. Because the perspectives of people familiar with the individual's behavior and needs often differ from self-perceptions 
(De Los Reyes, 2013), a sub-aim was to assess differences in priorities between adult women versus parents of adult women with TS and (b) perform a quantitative audit of the balance between biomedical and psychological research in the peer-reviewed literature on TS published in the past 10 years (2008-2018).

\section{2 | METHODS}

The study comprised two components: (a) a survey of TS-affected stakeholders and (b) a categorization and quantification of the peerreviewed medical and other scientific literature on TS as either biomedical or psychological.

\section{1 | Patient and parent survey}

\subsection{1 | Participants}

Participants were recruited through email lists belonging to the Turner Syndrome Society of the United States (TSSUS) and the Turner Syndrome Global Alliance (TSGA)-totaling 6,468-and their respective Facebook pages. The organizations were unable to indicate whether the email addresses were associated with a girl/woman with TS, a parent, a healthcare provider or researcher, or other person interested in the organizations' activities. Accordingly, the email and Facebook invitations, and the opening page of the survey, indicated eligibility for the survey (see below). There were a total 1,338 survey respondents; adult women (age 18 and older) with TS ( $n=543$ ), parents of an adult daughter (age 18 and older) with TS ( $n=232$ ), and parents of a daughter with TS, age 0-17 $(n=563)$. Participants resided in all 50 states (Table 1 ).

\section{2 | Procedures}

\subsection{1 | Survey development, design and administration}

Survey items were developed in consultation with leadership of the TSSUS, the TSGA, and members of TSSUS's Professional Advisory Board. The survey was adapted for three groups: adult women (age 18 and older) with TS; parents of an adult daughter (age 18 and older) with TS; and parents of a daughter (age 0-17) with TS. The multipart survey included questions covering: demographics; accompanying features of TS and their impact on daily life and well-being; health care delivery; growth hormone treatment; confidence in participating in one's health care (i.e., experienced self-efficacy); and priorities for research. The current article focuses on responses to items dealing with research priorities.

Three questions assessed the importance of (a) different areas of research, (b) the single most important area of research, and (c) willingness to participate in different types of research. Questions included the following: "How important is health research related to TS in the following areas?" (medical/physical health problems; emotional/behavioral health problems, including difficulty with relationships; and opportunities to participate in TS research studies; 3-point scale: very important, somewhat important, not important); "The most important health research related to TS should focus on:" (medical/physical health problems; emotional/behavioral health problems including difficulty with relationships; other; or do not know); and, How likely would you
TABLE 1 Participant demographics

\begin{tabular}{|c|c|c|c|c|}
\hline & $\begin{array}{l}\text { Women, } \\
\text { parent- } \\
\text { report } \\
(n=232)\end{array}$ & $\begin{array}{l}\text { Women, } \\
\text { self- } \\
\text { report } \\
(n=543)\end{array}$ & $\begin{array}{l}\text { Girls, } \\
\text { parent- } \\
\text { report } \\
(n=563)\end{array}$ & \\
\hline \multicolumn{3}{|l|}{ Race } & \multicolumn{2}{|l|}{ Race } \\
\hline White & $85 \%$ & $85 \%$ & White & $85 \%$ \\
\hline Not white & $15 \%$ & $15 \%$ & Not white & $15 \%$ \\
\hline \multicolumn{3}{|l|}{ Age (years) } & \multicolumn{2}{|l|}{ Age (years) } \\
\hline $18-29$ & $76 \%$ & $24 \%$ & $0-4$ & $20 \%$ \\
\hline $30-39$ & $19 \%$ & $29 \%$ & $5-10$ & $36 \%$ \\
\hline $40-49$ & $4 \%$ & $22 \%$ & $10-13$ & $20 \%$ \\
\hline $50+$ & $1 \%$ & $25 \%$ & $14-17$ & $24 \%$ \\
\hline \multicolumn{3}{|l|}{ Education } & \multicolumn{2}{|l|}{ Education } \\
\hline $\begin{array}{l}\text { High school } \\
\text { or less }\end{array}$ & $22 \%$ & $8 \%$ & $\begin{array}{l}\text { Preschool-5th } \\
\text { grade }\end{array}$ & $54 \%$ \\
\hline $\begin{array}{l}\text { Some college/ } \\
\text { trade }\end{array}$ & $42 \%$ & $22 \%$ & 6th-8th grade & $21 \%$ \\
\hline \multirow[t]{2}{*}{ College grad } & \multirow[t]{2}{*}{$36 \%$} & \multirow[t]{2}{*}{$70 \%$} & 9th-12th grade & $20 \%$ \\
\hline & & & Not in school & $5 \%$ \\
\hline \multicolumn{3}{|l|}{ Income } & \multicolumn{2}{|l|}{ Income $\mathrm{a}^{\mathrm{a}}$} \\
\hline$\leq \$ 60 k$ & $57 \%$ & $57 \%$ & $\leq \$ 60 k$ & $25 \%$ \\
\hline$>\$ 60 k$ & $18 \%$ & $25 \%$ & $>\$ 60 \mathrm{k}$ & $60 \%$ \\
\hline Not reported & $25 \%$ & $19 \%$ & Not reported & $15 \%$ \\
\hline
\end{tabular}

Note: Percentages are adjusted for missing data; "Income": "Not reported" comprises the responses of "Do not know" and "Prefer not to answer."

a "Income" for "Girls" refers to household of origin.

be to take part in the following types of health research related to TS? (a new medicine; a new medical device; surveys about eating/nutrition and quality of life; and study of DNA; 3-point scale: very likely, somewhat likely, not likely). The wording of the first two items was identical in the adult self-report and parent-report survey versions. Wording for the third item substituted "your daughter" for "you" in the parent-report survey. Survey items and response scales are presented in Supporting Information Appendix A.

The cross-sectional, web-based survey-fielded between April 21 and May 18, 2016-was programmed using Qualtrics (Qualtrics, Provo, UT). Pretesting with a convenience sample was performed to ensure questions were understood as intended. The email invitation and Facebook post disclosed the survey's purpose ("understanding the specific identified health care needs of those with TS"), the study investigators ("TSSUS, TSGA, and the TS health care community"), and the anticipated time to complete the survey ("a 15-min research survey"). Email reminders were sent to nonresponders 7, 14, and 21 days after the survey was originally fielded to improve response rates.

Based on a review of survey content and the procedures adopted for data collection, the University of Michigan Institutional Review Board considered the survey "exempt" because the data collected were anonymous and not sensitive in nature. Completion of the online survey constituted respondents' consent to participate in the investigation.

\section{3 | Statistical analysis}

\subsection{1 | Stakeholder priorities}

Descriptive statistics (frequencies and percentages) for the entire sample were calculated to characterize sample socio-demographics 
(Table 1). The first set of analyses involved a comparison of the three respondent groups (women with TS, age 18+; parents of women with TS, age 18+; and parents of a daughter with TS, age 0-17). These analyses did not take demographic factors into account because of their variable relationship to the respondent, (i.e., for the adult groups, the demographics were those of the woman with TS, regardless of whether the informant was the woman herself or a parent). In contrast, for the TS group age 0-17, key demographics (i.e., education and income) described the family of origin. For this reason, comparisons across the three groups for this first set of analyses were performed by unadjusted chi-square.

For most purposes, surveys of experiences and preferences rely on responses obtained from the targeted group. However, if there are reasons to question such reports, then information from people who know the person being assessed can improve understanding (Achenbach, 2006; Achenbach, Krukowski, Dumenci, \& Ivanova, 2005; De Los Reyes, 2013). In light of the well-documented neurocognitive profile of TS (Gravholt et al., 2017), with salient psychosocial features, the second set of analyses focused on comparisons between self-report and parent-report within the adult samples. Women with TS and parents of women with TS were recruited independently (i.e., there was no matching). Because of marked skewness in the distribution of responses in the direction of rating items as very important/very likely, response options of somewhat important/somewhat likely and not important/not likely were combined. In this set of analyses, we performed multivariate logistic regression to examine the importance (very important vs. [somewhat important, not important]) of research focusing on: (a) medical/physical health problems; (b) emotional/behavioral health problems, including difficulty with relationships; and (c) opportunities to participate in TS research. Multinomial logistic regression analysis was also used to study what respondents reported was the most important (most important vs. not) health research area: "medical/physical," "emotional/behavioral," or "other" (write-in). Inspection of the write-in responses categorized as "other" (88) showed that 84 participants (95\%) indicated "medical/physical" and "emotional/behavioral" were considered of equal importance. We therefore recoded these responses as "both" and the logistic regression analysis was rerun comparing the choices of "medical/physical" versus "both."

Finally, another set of multivariate logistic regression analyses was conducted to examine the likelihood (very likely vs. not likely) of participation in research studies of (a) new medicine, (b) new medical device, (c) eating/nutrition, (d) quality of life, and (e) DNA/genes. The main factor of interest was survey group: women with TS (parentreport) versus women with TS (self-report). In all models, we adjusted for race (White vs. Non-White), age group (18-29; 30-39; 40-49; and $50+$ ), education (high school or less; some college/trade; college grad) and income ( $<=\$ 60,000 ;>\$ 60,000$; not reported). For each model, we generated the predicted probability of the outcome by adult survey group (parent-report vs. self-report) adjusted for covariates. Stata/SE 15.0 was used for all analyses.

\subsection{2 | Audit of peer-reviewed literature}

To quantify the proportionality between studies focusing on either the biomedical versus psychological aspects of TS, we chose two representative electronic abstracting and indexing databases, PubMed $^{\circledR}$ and PsycINFO ${ }^{\circledR}$. Searches in both databases were restricted to documents focusing on "humans" and published in English between September 2008 and September 2018. We performed two searches in each database on September 24, 2018. The first round identified items for which "Turner syndrome" was the major focus of the article. The second round limited the first search to research with a psychological focus. Documents not classified as psychological were categorized as biomedical. Search terms were refined by examining a random sample of 40 PubMed $^{\circledR}$ entries (20 biomedical and 20 psychological) and all PsycINFO ${ }^{\circledR}$ results to maximize true positives. Duplicates were removed using EndNote ${ }^{\mathrm{TM}}$ software. See Supporting Information Appendix B for search terms and validation of categorization.

\section{3 | RESULTS}

\section{1 | Research priorities according to patient and parent stakeholders}

\subsubsection{Relative importance of research}

A significantly lower percentage of women rated research on medi$\mathrm{cal} /$ physical problems (90\%; $p=0.034$ ) and emotional/behavioral problems (84\%; $p<0.001)$ as "very important" compared with parents (94\% and $91 \%$ for parents of adult and younger daughters, respectively). The percentages of all three groups were substantially lower for the item inquiring about willingness to participate in any TSrelated research without differences detected ( $p=0.497$, Figure 1 ). Statistically adjusting for differences in demographic variables, the reports of women with TS were not significantly different from parents of adult daughters with TS for the same three survey items (Table 2). Notably, demographic variables were not systematic modifiers of the relationship between informant (self-report vs. parentreport) and responses regarding importance of research.

\subsection{2 | Research of most importance}

The options for the item "The most important health research related to TS should focus on:" included "medical/physical health problems," "emotional/behavioral health problems, including difficulty with relationships," "other" or "do not know." Of the total 1,234 respondents completing this item, $40.6 \%$ selected research with a medical/physical focus and $30.8 \%$ with an emotional/behavioral focus. Examination of the writein responses for the "other" option revealed that $6.8 \%$ indicated they viewed the different types of research as equally important. For the purposes of this set of analyses, a new category of "both" (medical/physical and emotional/behavioral) was created. Only $0.3 \%$ of those providing a write-in response for "other" noted a research priority not covered by the two major categories. An additional 5.9\% responded "do not know" and 15.6\% did not complete the item.

A comparison of the three survey groups revealed a statistically significant difference $(p=0.004)$ in ratings of most important focus for research. Approximately two-thirds (63.2\%) of the adults prioritized medical/physical research compared with $48.3 \%$ of the parents with an adult daughter. Parents reporting for younger daughters prioritized medical/physical (54.3\%) over emotional/behavioral (45.7\%) research (Figure 2a). 


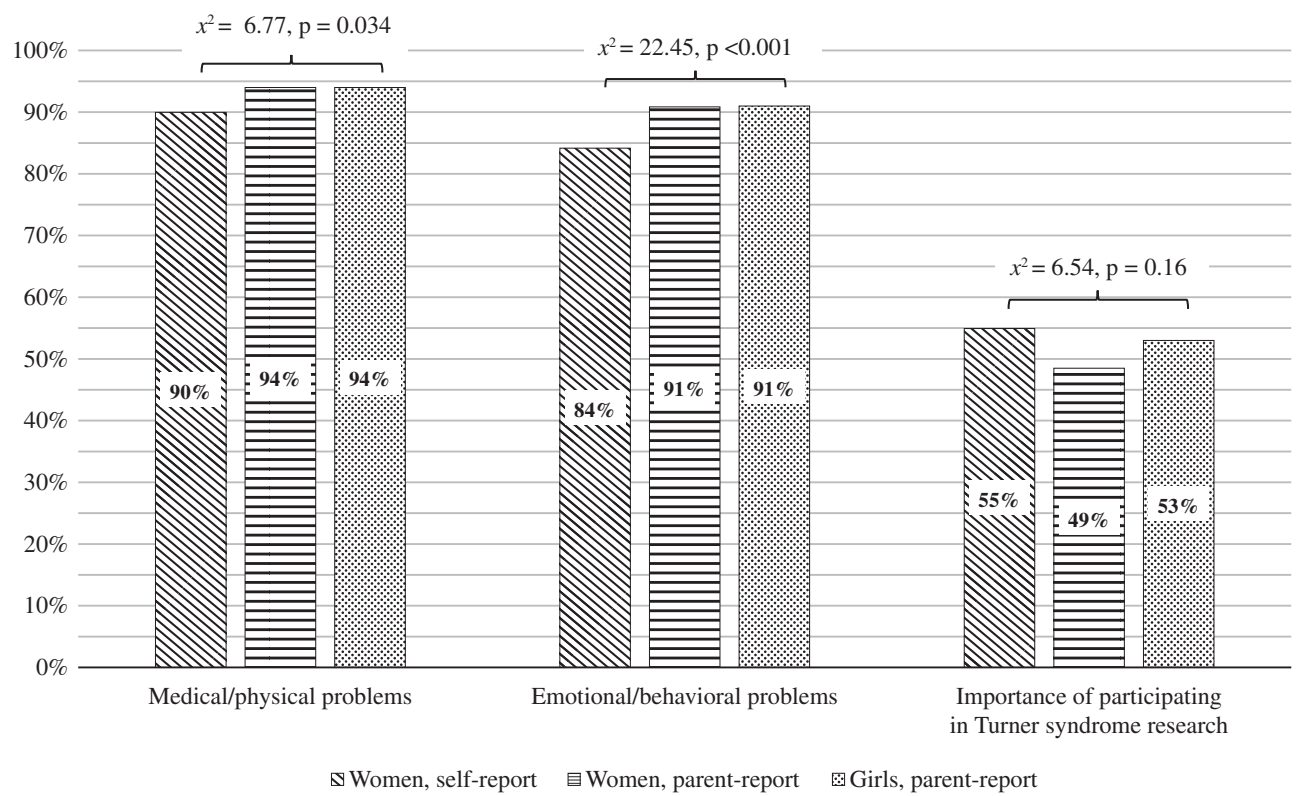

FIGURE 1 Importance of health research related to Turner syndrome: percentage selecting "very important" (versus NOT - not shown) for 3 survey items

Within the adult TS group, where it was possible to adjust for demographic variables, the odds were significantly lower $(O R=0.607,95 \% \mathrm{Cl}$, $0.375,0.982$ ) that women (self-report) prioritized emotional/behavioral over medical/physical research compared with proxy reports by parents (Table 3, left columns). Analyses were repeated, contrasting those respondents choosing "medical/physical" versus "both": a significant difference was not detected between the three respondent groups ( $p=0.228$; Figure $2 b$ ). Similarly, there was no difference between adult self- and parent-reports in the logistic regression taking into account background demographics (Table 3 , right columns).

TABLE 2 Multivariate logistic regression analyses of importance of different types of research and importance of participating in research (very important vs. not) among women with Turner syndrome; self-report versus parent-report

\begin{tabular}{|c|c|c|c|c|c|c|}
\hline \multirow[b]{2}{*}{ Predictor } & \multicolumn{2}{|c|}{ Medical/physical research } & \multicolumn{2}{|c|}{$\begin{array}{l}\text { Emotional/behavioral } \\
\text { research }\end{array}$} & \multicolumn{2}{|c|}{$\begin{array}{l}\text { Importance of participating in } \\
\text { Turner syndrome research }\end{array}$} \\
\hline & OR & $95 \% \mathrm{Cl}$ & OR & $95 \% \mathrm{Cl}$ & $\overline{O R}$ & $95 \% \mathrm{Cl}$ \\
\hline \multicolumn{7}{|l|}{ Participant $^{a}$} \\
\hline Women, self-report & 0.574 & {$[0.243,1.353]$} & 0.527 & {$[0.243,1.146]$} & 1.307 & {$[0.837,2.041]$} \\
\hline \multicolumn{7}{|l|}{ Race $^{\text {b }}$} \\
\hline White & 2.320 & {$[1.105,4.875]$} & 1.393 & {$[0.679,2.858]$} & 0.773 & {$[0.458,1.305]$} \\
\hline 30-39 years old & 1.383 & {$[0.581,3.296]$} & 0.547 & {$[0.255,1.175]$} & 1.729 & {$[1.059,2.824]$} \\
\hline $40-49$ years old & 0.936 & {$[0.383,2.287]$} & 0.474 & {$[0.211,1.065]$} & 1.114 & {$[0.640,1.938]$} \\
\hline $50+$ years old & 1.246 & {$[0.484,3.209]$} & 0.405 & {$[0.181,0.906]$} & 1.479 & {$[0.847,2.585]$} \\
\hline \multicolumn{7}{|l|}{ Education $^{d}$} \\
\hline Some college/trade & 1.049 & {$[0.343,3.209]$} & 0.757 & {$[0.262,2.185]$} & 1.360 & {$[0.754,2.451]$} \\
\hline Unknown & 0.691 & {$[0.327,1.463]$} & 0.797 & {$[0.413,1.539]$} & 0.747 & {$[0.478,1.166]$} \\
\hline Predicted probability (PP) & $\mathrm{PP}$ & SE & $\mathrm{PP}$ & SE & $\mathrm{PP}$ & SE \\
\hline \multicolumn{7}{|l|}{ Survey group } \\
\hline Women, parent-report & $93.95 \%$ & $2.13 \%$ & $90.86 \%$ & $2.94 \%$ & $48.50 \%$ & $4.48 \%$ \\
\hline Women, self-report & $89.97 \%$ & $1.54 \%$ & $84.16 \%$ & $1.78 \%$ & $54.93 \%$ & $2.53 \%$ \\
\hline
\end{tabular}

$\mathrm{Cl}=$ confidence interval; $\mathrm{OR}=$ odds ratio. Bolded $\mathrm{OR}$ and associated $95 \% \mathrm{Cl}$ indicates statistically significant difference compared with reference category,

$S E=$ standard error.

Reference categories:

a Women, parent-report.

b Non-White.

c 18-29 years old.

${ }^{d} \mathrm{HS}$ or less.

e $\leq 60 \mathrm{k}$. 


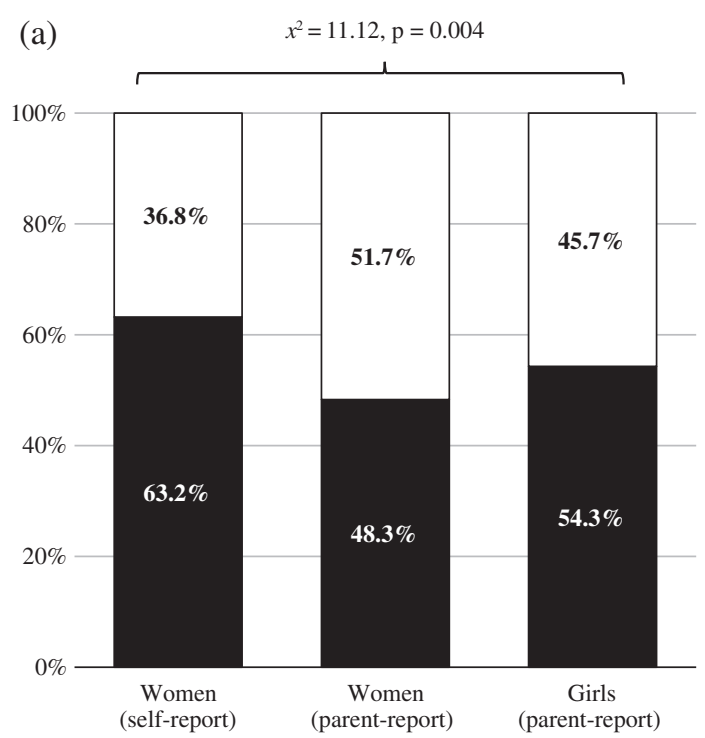

- Medical/Physical $\square$ Emotional/Behavioral

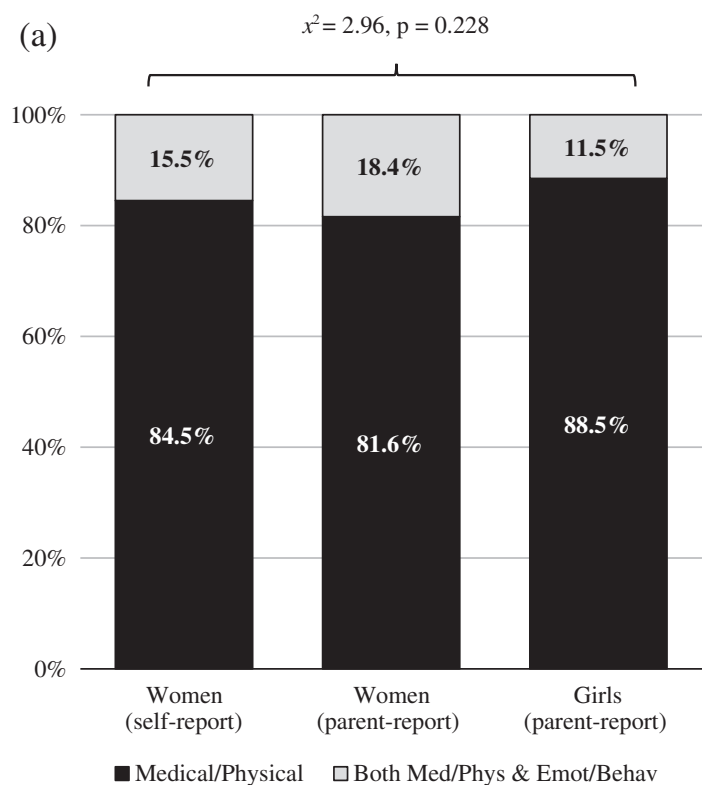

FIGURE 2 Research focus of most importance: medical/physical versus emotional/behavioral

\subsection{3 | Willingness to participate in research of different types}

Significant differences in willingness to participate across the three groups was observed for studies of "new medicine" $(p=0.021)$ and "eating and nutrition" ( $p=0.005$; Figure 3$)$. The likelihood of participating in research was highest for studies of eating or nutrition, quality of life, and genetic research (range: $59 \%-73 \%$ ) and lowest for studies of new medicines or medical

TABLE 3 Multinomial logistic regression analysis for item inquiring about "most important" health research related to Turner syndrome among women with Turner syndrome; self-report versus parent-report

\begin{tabular}{|c|c|c|c|c|c|c|}
\hline \multirow[b]{2}{*}{ Predictor } & \multicolumn{3}{|c|}{ Medical/physical vs. emotional/behavioral research } & \multicolumn{3}{|c|}{ Medical/physical research vs. both ${ }^{\mathrm{a}}$} \\
\hline & \multicolumn{2}{|l|}{ OR } & \multirow[t]{2}{*}{$95 \% \mathrm{Cl}$} & OR & \multicolumn{2}{|l|}{$95 \% \mathrm{Cl}$} \\
\hline \multicolumn{6}{|l|}{ Participant ${ }^{\mathrm{b}}$} & \\
\hline \multicolumn{7}{|l|}{$\operatorname{Race}^{c}$} \\
\hline White & \multicolumn{2}{|l|}{0.799} & {$[0.456,1.401]$} & 2.299 & \multicolumn{2}{|c|}{$[0.659,8.023]$} \\
\hline \multicolumn{7}{|l|}{ Age group $^{d}$} \\
\hline $40-49$ years old & \multicolumn{2}{|l|}{0.736} & {$[0.404,1.343]$} & 2.421 & \multicolumn{2}{|c|}{$[0.845,6.935]$} \\
\hline $50+$ years old & \multicolumn{2}{|l|}{0.511} & {$[0.273,0.956]$} & 2.909 & \multicolumn{2}{|c|}{$[1.033,8.190]$} \\
\hline \multicolumn{7}{|l|}{ Education ${ }^{\mathrm{e}}$} \\
\hline Some college/trade & \multicolumn{2}{|l|}{1.229} & {$[0.627,2.410]$} & 0.363 & \multicolumn{2}{|c|}{$[0.139,0.951]$} \\
\hline College grad & \multicolumn{2}{|l|}{1.578} & {$[0.809,3.077]$} & 0.338 & \multicolumn{2}{|c|}{$[0.137,0.834]$} \\
\hline Unknown & \multicolumn{2}{|c|}{ Medical/physical } & Emotional/beh & & \multicolumn{2}{|l|}{ Both } \\
\hline Predicted probability (PP) & PP & $S E$ & $\mathrm{PP}$ & $S E$ & PP & SE \\
\hline \multicolumn{7}{|l|}{ Survey group } \\
\hline Women, parent-report & $43.88 \%$ & $4.65 \%$ & $44.91 \%$ & $4.58 \%$ & $11.21 \%$ & $3.29 \%$ \\
\hline Women, self-report & $55.49 \%$ & $2.68 \%$ & $34.75 \%$ & $2.57 \%$ & $9.76 \%$ & $1.50 \%$ \\
\hline
\end{tabular}

$\mathrm{Cl}=$ confidence interval; $\mathrm{OR}=$ odds ratio; Bolded $\mathrm{OR}$ and associated $95 \% \mathrm{Cl}$ indicates statistically significant difference compared with reference category, $S E=$ standard error.

Reference categories:

a "Both" refers to respondent choosing "Other" category and writing in that both types of research are equally important.

${ }^{b}$ Women, parent-report.

c Non-White.

d 18-29 years old.

e high school or less.

$\mathrm{f} \leq 60 \mathrm{k}$. 


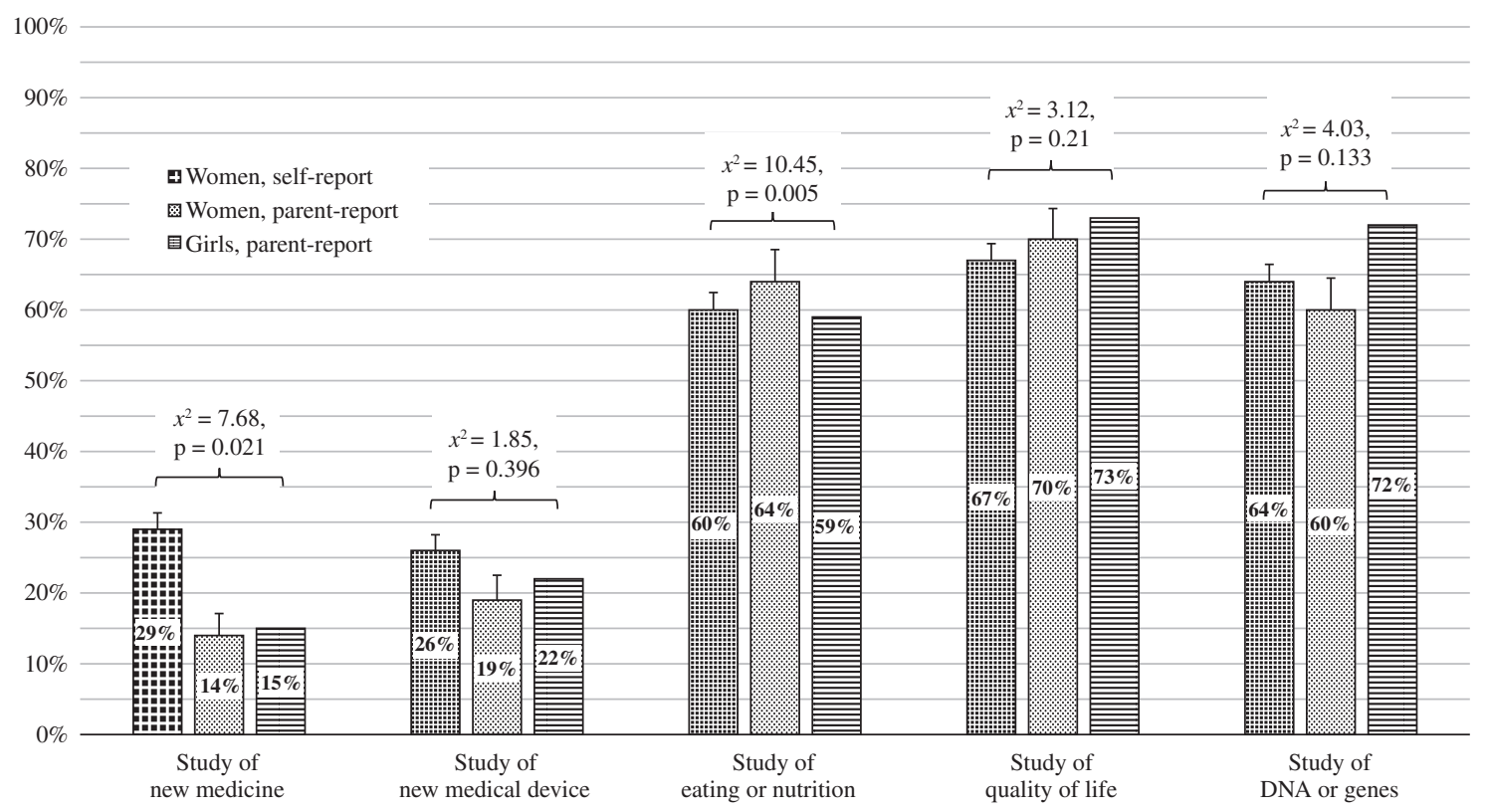

FIGURE 3 Likelihood of participating in various type of health research related to Turner syndrome. Chi-square tests performed as 3 (respondent group) $\times 2$ ("very likely" vs. [NOT]), without adjustments for demographics. Percentages reported for women (self-report) and women (parentreport) are adjusted for race, age, education, and income and are reported as predicted probability ( \pm SE; see also Table 3 )

device (range: 14\%-29\%). When adult respondents-self-report versus parent-report-were compared by multivariate logistic regression, adjusting for background demographic variables, no differences were detected in willingness to participate in any of the types of research (Table 4).

\section{2 | Balance between biomedical and psychological research in the peer-reviewed literature}

The PubMed ${ }^{\circledR}$ search returned 1,122 items: 1,042 biomedical (19/20 confirmed true positives in review of 20 randomly items) and 80 psychological (20/20 true positives). The psycINFO ${ }^{\circledR}$ search generated a total of 91 items: 37 biomedical (33/37 true negatives) and 54 psychological (51/54 true positives) items. In total, across the two databases, we found 1,151 biomedical-focused (90.96\%) items and 104 psychological-focused items (9.04\%).

\section{4 | DISCUSSION}

The recently published clinical practice guidelines (Gravholt et al., 2017) for TS comprehensively identify the features of the condition, their evaluation and treatment strategies. They highlight the depth of knowledge gained through discovery and clinical experience regarding both the biomedical and neurocognitive and psychosocial aspects of TS. The objective of this survey was to assess how those affected by TS, identified through their associations with TS-support and advocacy organizations, weigh the importance of these different research directions.

The overwhelming majority of all three groups of survey respondents-between $84 \%$ and $94 \%$-rated both biomedical and psychosocial research as "very important." Notwithstanding the observation that women with TS rated both types of research as less important than parents of affected women or girls, our audit of the peer-reviewed literature suggests a very different priority within the research community: $91 \%$ of published studies focused on biomedical aspects of TS and only $9 \%$ on psychological variables. Another way of presenting the apparent mismatch between the research priorities of those affected by TS and the emphasis in published studies is to focus on the domain considered by respondents to be of most importance. The women's self-report showed that $63 \%$ designated biomedical research as most important, followed by $54 \%$ and $48 \%$ of the parents of daughters less than 18 years and parents of adult daughters, respectively.

There are two inferences to be made from these findings, one straightforward and the other cautious. The obvious conclusion is that there is much greater balance across all survey respondent groups in prioritizing biomedical and psychological literature than what is represented from an audit of the scientific literature over the past 10 years. The more cautious inference involves interpretation of the statistically significant difference between women with TS and parents of adult daughters in the assignment of greatest importance to biomedical versus psychological research. Parents viewed psychological research as the highest priority (52\%) compared with a significantly lower proportion (37\%) of women themselves. Assuming that priorities for research are driven, in part, by perceptions of personal relevance, one might speculate the difference between parents and affected adults is attributable to the women's reduced capacity to accurately judge their own psychosocial adaptation, based on the well-documented neurocognitive profile in TS (Gravholt et al., 2017; pp. G43-G49).

Another notable survey finding concerned willingness to participate in research: whereas between $84 \%$ and $94 \%$ of the three respondent groups rated research (either biomedical or psychological) as "very important," only $49 \%-55 \%$ rated opportunities to participate in research 


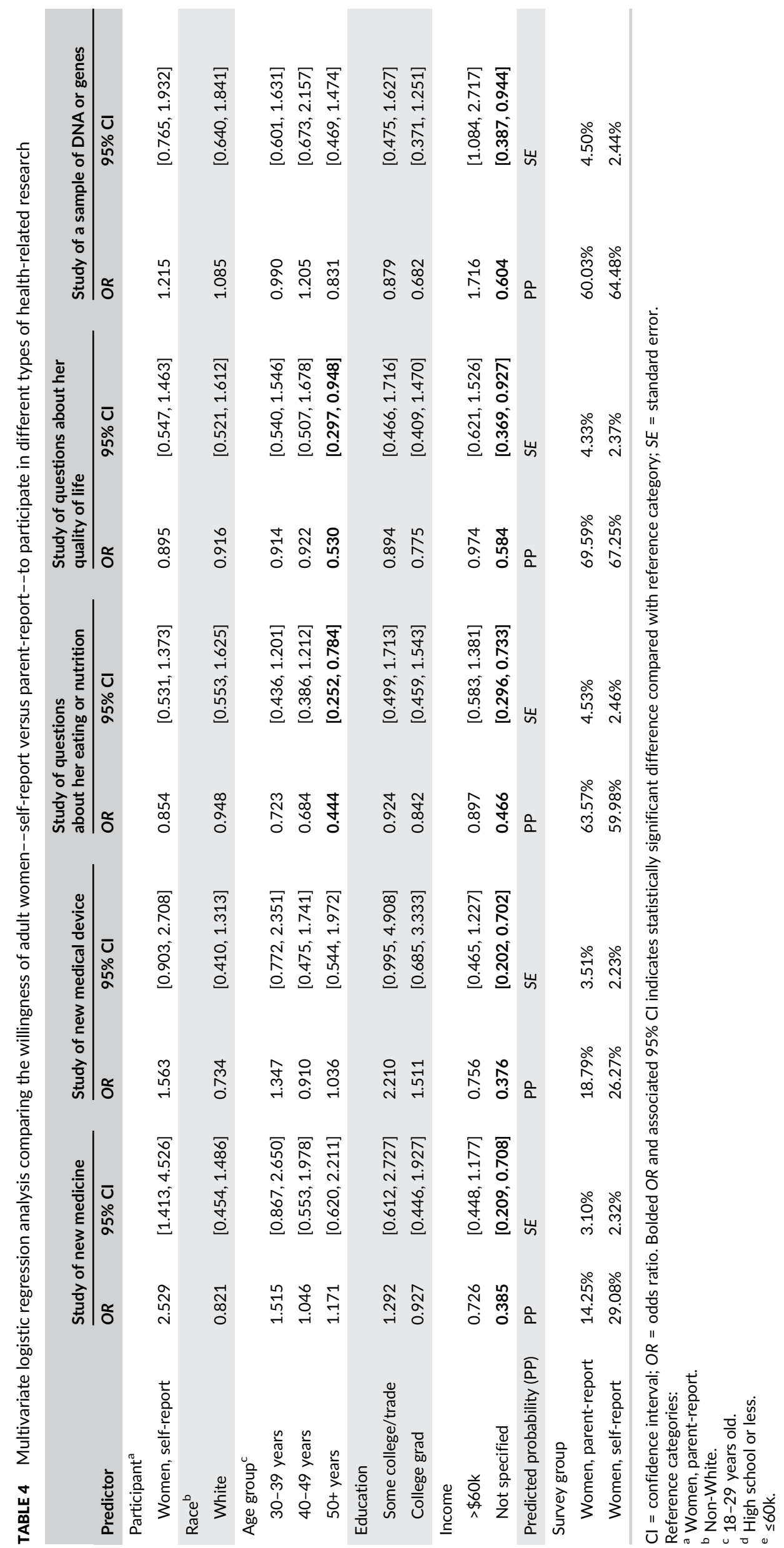


as very important. Time will tell whether ongoing efforts by TS-support and advocacy organizations to inform patient and family stakeholders about the importance of various forms of research and reduce barriers to confidential participation will gradually lead to increased willingness to participate (Turner Syndrome Research Registry, 2018).

Finally, the survey showed stable differences across the three independent respondent groups in likelihood of participating in five categories of research pertinent to TS: survey participants were far more likely to participate in studies of eating or nutrition, quality of life, and genetics than studies on new medicines or medical devices. Insofar as participants were not asked to provide reasons for choices, one can only speculate as to the underpinnings of the stated likelihoods of participating.

The current study is characterized by both strengths and limitations. The participant numbers were relatively high compared to other studies in TS. It is also distinguished by targeting the perspectives of a wide age range of affected stakeholders, including both self- and parent informants. Yet the inclusion of parents with an adult daughter with TS who were not matched to adult participants is a limitation. The National Organization of Rare Diseases (NORD) estimates more than 70,000 women and girls in the United States have TS. Moreover, NORD reports there are no known racial or ethnic factors influencing the incidence of TS. By contrast, our survey represented the perspectives of 563 girls and 543 women with TS, as well as that of 232 parents, all of whom were identified through the email lists of the Turner Syndrome Society the US, the Turner Syndrome Global Alliance, or their affiliated Facebook pages. Furthermore, $85 \%$ of respondents were White, compared with $61 \%$ in the US general population (United States Census Bureau, 2017). Accordingly, generalizations from these findings to the total population of girls and women with TS and their parents must be made cautiously.

In conclusion, the findings from this relatively large sample of girls and women with TS, and their parent stakeholders, suggest the medical and other scientific literature on TS is overweighted toward biomedical discovery and underweighted with regard to psychological research when the priorities of the TS community are used as the benchmark. Increased engagement of patient and other stakeholders in research requires that investigators select topics of study which are important to that community (Forsythe et al., 2014). By doing so, researchers not only build trust, but raise the potential of promoting stronger collaborative networks. The National Health Service of the United Kingdom adopted the phrase "no decision about me, without me" as the motto guiding service delivery within their healthcare system (National Health Service, 2012). Although this patient-centered approach is focused on achieving better clinical care and treatment through opportunities for patients to be more actively involved in decisions regarding care, this approach must also apply to the types of research conducted that identify patient and family-prioritized treatments and outcomes (Frank et al., 2015).

\section{ACKNOWLEDGMENT}

The authors thank the survey participants for sharing their perspectives. The authors are also grateful to Barbara Lippe MD, Judith
Ross MD, and Kelly Ranallo (Turner Syndrome Global Alliance) for their guidance regarding construction and execution of the survey, and Melissa Gardner for assistance with data analysis. This work was supported, in part, by a conference grant (R13HD096857; 2018 Turner Resource Network Symposium "Turner Science in the 21st Century") and research project grant (R01 HD093450; Disorders/Differences of Sex Development-Translational Research Network) from the Eunice Kennedy Shriver National Institute of Child Health and Human Development. Support was also received from the Patient-Centered Research Institute through a Eugene Washington PCORI Engagement Award.

\section{CONFLICT OF INTEREST}

The authors declare that they have no conflict of interest regarding the content of this manuscript.

\section{ORCID}

David E. Sandberg (D) https://orcid.org/0000-0002-7389-8283

\section{REFERENCES}

Achenbach, T. M. (2006). As others see us: Clinical and research implications of cross-informant correlations for psychopathology. Current Directions in Psychological Science, 15(2), 94-98. https://doi.org/ 10.1111/j.0963-7214.2006.00414.x

Achenbach, T. M., Krukowski, R. A., Dumenci, L., \& Ivanova, M. Y. (2005). Assessment of adult psychopathology: Meta-analyses and implications of cross-informant correlations. Psychological Bulletin, 131(3), 361382. https://doi.org/10.1037/0033-2909.131.3.361

Committee on Quality of Health Care in America, \& Institute of Medicine. (2001). Crossing the quality chasm: A new health system for the 21st century. Washington, DC: The National Academies Press.

De Los Reyes, A. (2013). Strategic objectives for improving understanding of informant discrepancies in developmental psychopathology research. Development and Psychopathology, 25(3), 669-682. https:// doi.org/10.1017/S0954579413000096

Forsythe, L. P., Szydlowski, V., Murad, M. H., Ip, S., Wang, Z., Elraiyah, T. A., ... Hickam, D. H. (2014). A systematic review of approaches for engaging patients for research on rare diseases. Journal of General Internal Medicine, 29(3), 788-800. https://doi.org/10.1007/s11606014-2895-9

Frank, L., Forsythe, L., Ellis, L., Schrandt, S., Sheridan, S., Gerson, J., ... Daugherty, S. (2015). Conceptual and practical foundations of patient engagement in research at the patient-centered outcomes research institute. Quality of Life Research, 24, 1-9. https://doi.org/10.1007/ s11136-014-0893-3

Gravholt, C. H., Andersen, N. H., Conway, G. S., Dekkers, O. M., Geffner, M. E., Klein, K. O., ... Backeljauw, P. F. (2017). Clinical practice guidelines for the care of girls and women with turner syndrome: Proceedings from the 2016 Cincinnati international turner syndrome meeting. European Journal of Endocrinology, 177(3), G1-G70. https:// doi.org/10.1530/eje-17-0430

National Health Service. (2012). Liberating the NHS: No decision about me, without me-Government response to the consultation. (Gateway reference 18444). London. Retrieved from https://assets.publishing. service.gov.uk/government/uploads/system/uploads/attachment_data/ file/216980/Liberating-the-NHS-No-decision-about-me-without-meGovernment-response.pdf.

Turner Syndrome Research Registry. (2018). Retrieved from https://www. turnersyndrome.org/research-registry.

United States Census Bureau. (2017). Quick facts. Retrieved from https:// www.census.gov/quickfacts/fact/table/US/PST045217. 


\section{AUTHOR BIOGRAPHIES}

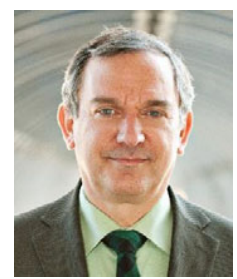

David E. Sandberg, PhD, is a professor of Pediatrics in the Division of Pediatric Psychology and Faculty Investigator in the Susan B. Meister Child Health Evaluation and Research (CHEAR) Center at the University of Michigan Medical School in Ann Arbor. Dr. Sandberg recently served as co-lead for the Neurocognition and Behavior section of the 2017 Clinical Practice Guidelines for The Care of Girls and Women with Turner Syndrome.

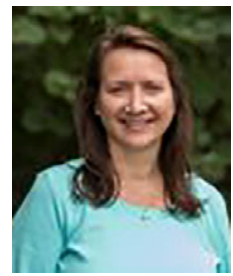

Dianne Singer, MPH, is a Project Manager in the Department of Pediatrics and the Institute for Healthcare Policy and Innovation at Michigan Medicine. Her research focuses on health services and health policy affecting children and older adults.

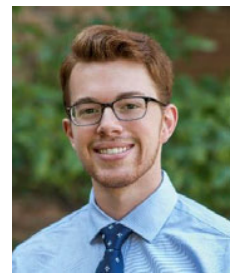

Benjamin Bugauski, BA, is a Research Associate in the Susan B. Meister Child Health Evaluation and Research (CHEAR) Center in the Department of Pediatrics at Michigan Medicine.

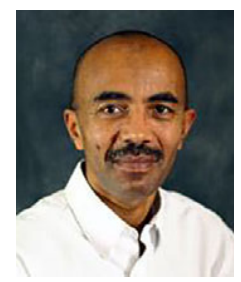

Achamyeleh Gebremariam, MS, is senior programmer analyst at the Susan B. Meister Child Health Evaluation and Research (CHEAR) Center in the Department of Pediatrics at the University of Michigan Medical School. He provides biostatistical support for CHEAR faculty in a variety of research areas.

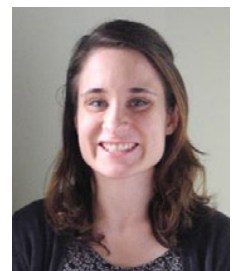

Teresa Screbak, BS, is a Research Associate in the Susan B. Meister Child Health Evaluation and Research (CHEAR) Center in the Department of Pediatrics at Michigan Medicine.

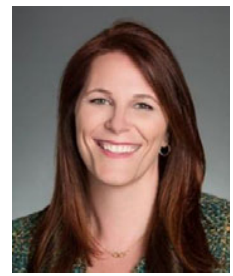

Kathleen L. Dooley Maley, AB, MA, is a board member of the Turner Syndrome Society of the United States and the parent of a sixyear-old with Turner syndrome. She is Senior Director of Client Analytics at KeyBank.

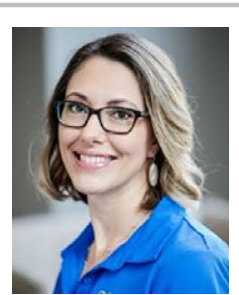

Cindy C. ScUrlock, MA is President and CEO of the Turner Syndrome Society of the United States and Co-Principal Investigator of the Turner Syndrome Research Registry. Her research interests are focused on solving issues related to Turner syndrome through collaboration with clinical researchers and patients and families.

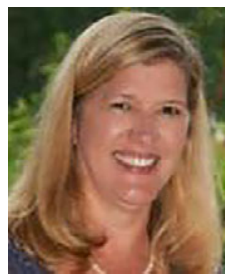

Denise D. Culin, RT, is co-founder and Executive Director at Turner Syndrome Global Alliance. She has committed more than 20 years to supporting the Turner syndrome community.

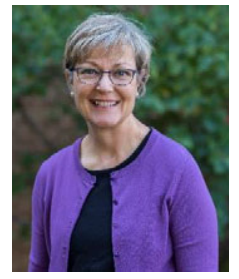

Sally Eder, BA, is Clinical Subjects Coordinator at Department of Pediatrics and the Susan B. Meister Child Health Evaluation and Research (CHEAR) Center, University of Michigan.

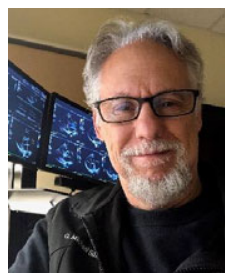

Michael Silberbach, MD is the Chairman of the Turner Resource Network (TRN) Steering Committee and Professor of Pediatrics in the Division of Pediatric Cardiology at Doernbecher Children's Hospital, Portland Oregon where he is the director of pediatric cardiac MRI. His research focuses on the growth of the aorta and the genetic mechanisms of aortopathy.

\section{SUPPORTING INFORMATION}

Additional supporting information may be found online in the Supporting Information section at the end of the article.

How to cite this article: Sandberg DE, Singer D, Bugajski B, et al. Research priorities of people living with Turner syndrome. Am J Med Genet Part C. 2019;181C:43-51. https://doi. org/10.1002/ajmg.c.31676 